\title{
Secondary Angle Closure Following Panretinal Yellow PASCAL Laser Photocoagulation
}

\section{Tatiana Vélez Osorio ${ }^{1 *}$, Nassim Abreu $^{2}$ and William McCollum ${ }^{3}$}

${ }^{1} 2^{\text {nd }}$ year Ophthalmology Resident at Hospital Dr. Elías Santana and Instituto Tecnológico de Santo Domingo, Dominican Republic

E-mail: Hes.oftalmologia.tvo@gmail.com

${ }^{2}$ Staff doctor of the Retina department of Hospital Dr. Elías Santana and Instituto Tecnológico de Santo Domingo, Dominican Republic

E-mail: Hes.oftamologia.naa@gmail.com

${ }^{3}$ Staff doctor of the Glaucoma department of Hospital Dr. Elías Santana and Instituto Tecnológico de SantoDomingo, Dominican Republic

E-mail: Hes.oftalmologia.wmm@gmail.com

Dr. Elías Santana and Instituto Tecnológico de Santo Domingo, Dominican Republic.

\begin{abstract}
Objective: To report the case of a patient with severe non-proliferative diabetic retinopathy who developed angle closure after undergoing retinal photocoagulation (PRP) with a yellow Pascal $577 \mathrm{~nm}$ laser.

Observation: 30-year-old male with severe non-proliferative diabetic retinopathy presented with severe ocular pain and nausea one day after undergoing laser photocoagulation in the left eye for the treatment of his diabetic retinopathy. His visual acuity was $20 / 200$ and his intraocular pressure (IOP) was 45 in his left eye. It had a shallow anterior chamber that was closed on gonioscopy. Ultrasonic biomicroscopy (UBM) reported an anterior chamber of $1.68 \mathrm{~mm}$ with narrow iridocorneal angles. He was managed with medications to reduce IOP, which included cycloplegics, topical and oral steroids. He was closely followed with serial examination and the intraocular pressure was reduced before developing glaucoma.

Conclusion: Patients presenting with ocular pain and increased IOP after laser photocoagulation should increase suspicion for angle closure. Limiting the number of laser burns and the amount of retinal area treated can prevent this problem from occurring.
\end{abstract}

Keywords: Secondary Angle Closure; Angle Closure Glaucoma; Retinal Pan-Photocoagulation

\section{Introduction}

Angle closure is a condition that can cause blindness if not treated. It can be triggered by a variety of causes that lead to a closure of the anterior chamber angle, with secondary increase in intraocular pressure due to the obstruction of the aqueous humor outlet. One of these causes is panretinal laser photocoagulation. This is one of the most performed outpatient ophthalmic procedures used in the treatment of occlusive vascular disorders of the retina such as diabetic retinopathy, ischemic venous occlusion, among others.

\section{Case Report}

A 30-year-old male patient with diabetes and hypertension with a diagnosis of diabetic retinopathy. He had 20/30 vision in the right eye and 20/100 in the left eye, intraocular pressures of $19 \mathrm{mmHg}$ in the right eye and $10 \mathrm{mmHg}$ in the left eye. The fundus examination revealed severe non-proliferative diabetic retinopathy and diabetic macular edema in the left eye. Panretinal photocoagulation is indicated in his left eye due to the high risk of progression to proliferative diabetic retinopathy as described in the ETDRS. 
A yellow $577 \mathrm{~nm}$ Pascal laser was used, with the following parameters: spot size of $200 \mu \mathrm{m}, 400$ - $550 \mathrm{mw}$ of power, energy 250 $\mathrm{mj}$, exposure time 20 milliseconds and a total of 2700 shots. The entire procedure was performed in one session, leaving 1 diameter of the nasal disc to the optic nerve and around the temporal vascular arch free of shots. After the procedure, he was sent home with anti-inflammatory treatment, which was not used by the patient. At 12 hours after the procedure, the patient had headache, nausea, and decreased visual acuity in the left eye and he came back to the clinic one day after the procedure with visual acuity $20 / 200$ in the left eye and 20/30 in the right eye. Slit lamp examination of the left eye demonstrated a clear cornea, narrow anterior chamber, van herick of 0 (Figure A), and elevated intraocular pressure (IOP) of $45 \mathrm{~mm}$ Hg by Goldmann tonometer Gonioscopy showed angle closure (Schaffer Grade 0) that did not open with indentation (Figure B and C). Ultrasonic biomicroscopy (UBM) was performed, which reported an anterior chamber of 1.68 (narrow) with closed iridocorneal angles (Figure G). Elevated intraocular pressure did not improve on the first day after administration of $250 \mathrm{mg}$ oral acetazolamide, intravenous mannitol, tropicamide with phenylephrine, triple topical hypotensive therapy, and oral and topical corticosteroid therapy.
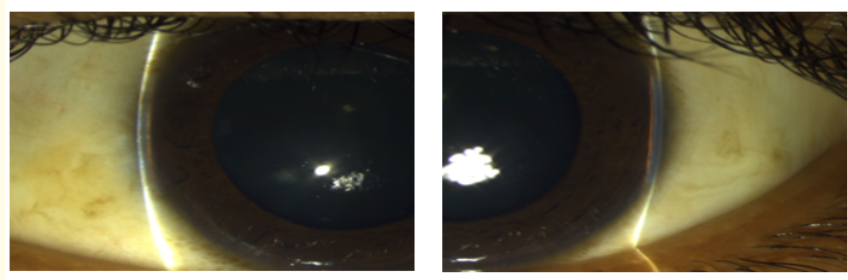

Figure A


Figure B
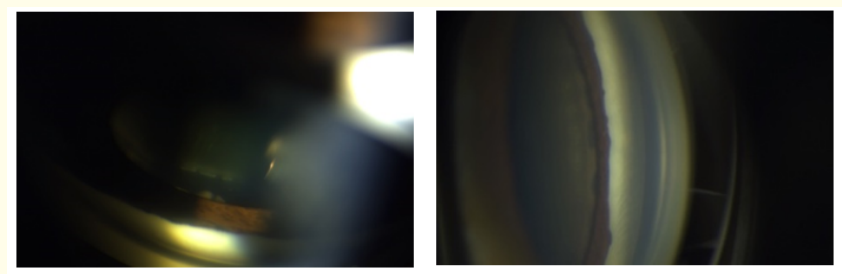

Figure C

He was evaluated the next day, and his IOP was lowered to 23 $\mathrm{mmHg}$, narrow anterior chamber, van herick of 1 , gonioscopy with Angle closure (Schaffer grade 0). He was continued on the same treatment regimen.

At the next follow-up visit, 2 days later, visual acuity was 20/100 in the left eye and intraocular pressure $12 \mathrm{mmHg}$ in both eyes. Ultrasonic biomicroscopy (UBM) reported an anterior chamber of 2.69 (Figure $\mathrm{H}$ ) demonstrated and increased anterior chamber depth compared to the previous visit.

Slit lamp examination revealed a clear cornea, wide anterior chamber, van herick of 3 (Figure D), gonioscopy showed open angles (Schaffer Grade 3) (Figure E and F).
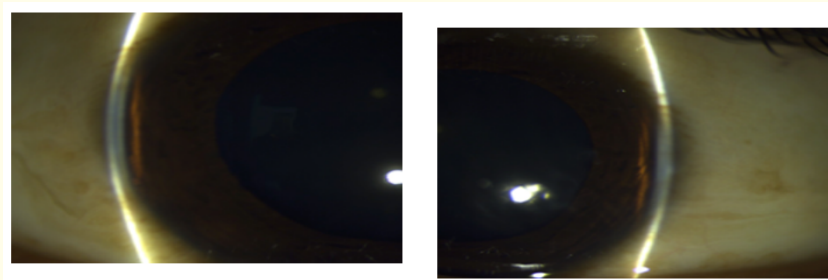

Figure D


Figure E 

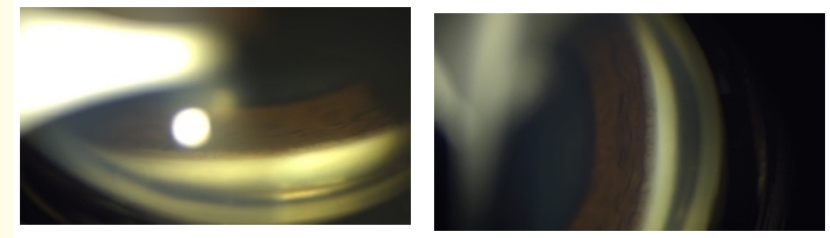

Figure F

The fundus examination showed an optic nerve with cup: disc ratio of 0.3 and multiple microhemorrhages and hard exudates were seen in the peripheral retina, besides the presence of yellow laser marks (Figure I). Elevated intraocular pressure improved after administration of oral acetazolamide $250 \mathrm{mg} 3$ times a day, triple topical therapy (Dorzolamide, timolol, brimonidine) twice a day, dorzolamide once a day, prednisolone acetate $1 \% 4$ times a day, systemic corticosteroid and tropicamide with phenylephrine 3 times an day. With this treatment, the patient was asymptomatic. Once the intraocular pressure stabilized, he continued with gradual reduction of his treatment until suspended.

Currently, 2 months later, he is off medication and the IOP is 17 $\mathrm{mmHg}$ in the right eye and $19 \mathrm{mmHg}$ in the left eye.

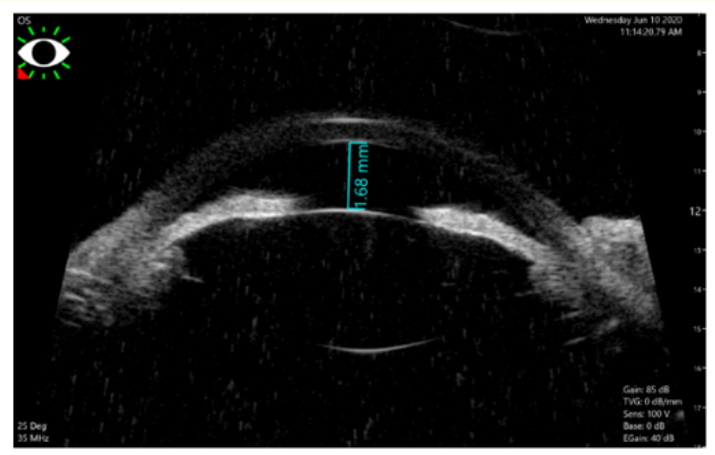

Figure G

\section{Discussion}

Pascal yellow $577 \mathrm{~nm}$ laser retinal photocoagulation (PRP) is a common ophthalmic procedure performed on eyes with severe non-proliferative retinopathy and proliferative retinopathy. Treat-



Figure H

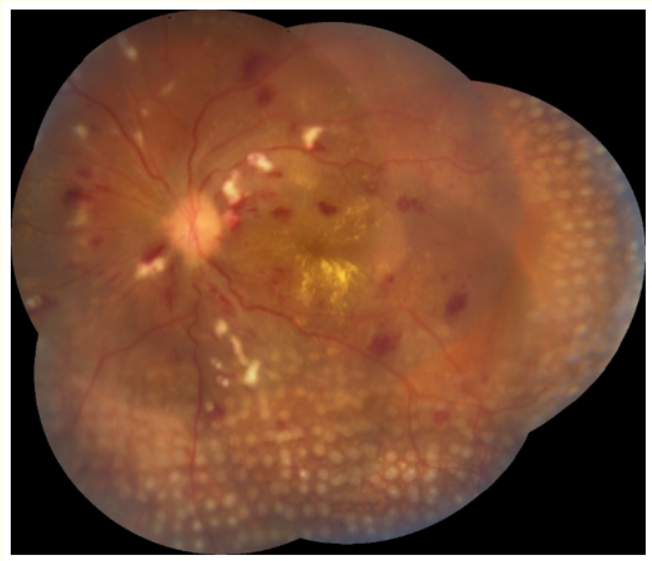

Figure I

ment is aimed at ablation of peripheral retinal tissue to reduce the ratio of oxygen supply to demand of the retina. This in turn reduces the hypoxic vaso-proliferative impulse which, if left unchecked, can lead to a painful, blind eye. This procedure reduces or eliminates the stimulus for the formation of new vessels and reduces the incidence of rubeosis iridis, angular neovascularization, and neovascular glaucoma [13].

Complications of PRP include thermal injury to the cornea, iris, and lens, visual field loss, hemorrhage, macular edema, and elevated intraocular pressure with or without angle closure. 
Transient increases in intraocular pressure after PRP are quite common, with $32 \%$ to $94 \%$ of patients experiencing an increase in IOP > $6 \mathrm{~mm} \mathrm{Hg}[1,11]$.

It appears that the amount of laser energy can influence the incidence and severity of pressure rise [6,11]. Blondeau hypothesized that lower levels of laser energy may be associated with a lower incidence and severity of IOP elevation after PRP [1].

Elevation of IOP after PRP may be due to open or closed angle mechanisms. Proposed open-angle mechanisms include: blockage of aqueous outflow due to compression of the episcleral veins; movement of fluid from the choroid to the vitreous secondary to the breakdown of the blood-retinal barrier; decreased uveoscleral outflow due to ciliary body congestion; Laser damage to the short ciliary nerves causes a decrease in the tone of the ciliary muscle, as well as the release of prostaglandins [1]. The pathogenesis behind the angle closure is believed to be due to inflammation of the ciliary body or the movement of fluid from the choroid to the vitreous secondary to a temporary weakening of the blood-retinal barrier, which can lead to anterior displacement of the iris lens diaphragm [1-6].

Mensher studied changes in anterior chamber depth and angle after PRP for diabetic retinopathy. All patients treated with laser presented narrowing of the anterior chamber and angle with closure of the angle in $31 \%$ [1-3].

In summary, A recent history of yellow pascal laser (PRP) should increase the index of suspicion for angle closure by $[1,5,8]$. The number of laser burns should be limited and the amount of retinal area treated can prevent this problem from occurring $[4,7]$.

Elevations in intraocular pressure generally respond to treatment with topical and oral cycloplegic agents, beta-blockers, adrenergic agonists, and carbonic anhydrase inhibitors, as needed to prevent optic nerve damage. In addition, topical and oral corticosteroids must be added to reduce inflammation of the ciliary body and thus avoid the angle closure mechanism.

\section{Conclusion}

Angle closure secondary to laser photocoagulation is a complication that could lead to permanent glaucoma damage. This yellow laser is considered a relatively safe and effective procedure that, due to its form of light emission, generates less heat and therefore less inflammation, which is why it is rarely associated with secondary angle closure. This case report demonstrates that this pathology can occur after laser photocoagulation, so every patient should be evaluated after performing the procedure. Furthermore, this case illustrates the importance of taking measures such as reducing laser energy.

\section{Bibliography}

1. Blondeau P., et al. "Acute pressure elevation following panretinal photocoagulation". Archives of Ophthalmology 99.7 (1981): 1239-1241.

2. Yuki T., et al. "Ciliary body and choroidal detachment after laser photocoagulation for diabetic retinopathy. A high-frequency ultrasound study". Ophthalmology 104.8 (1997): 1259-1264.

3. Mensher JH. "Anterior chamber depth alteration after retinal photocoagulation". Archives of Ophthalmology 95.1 (1977): 113-116.

4. Huamonte FU., et al. "Immediate fundus complications after retinal scatter photocoagulation. I. Clinical picture and pathogenesis". Ophthalmic Surgery 7.1 (1976): 88-99.

5. Kaufman SC., et al. "Intraocular pressure following panretinal photocoagulation for diabetic retinopathy. Diabetic Retinopathy Report No. 11". Archives of Ophthalmology 105.6 (1987): 807-809.

6. Gentile RC., et al. "Risk factors for ciliochoroidal effusion after panretinal photocoagulation". Ophthalmology 103.5 (1996): 827-832.

7. Liang JC and Huamonte FU. "Reduction of immediate complications after panretinal photocoagulation". Retina 4.3 (1984): 166-170.

8. Kapoor B., et al. "An unusual case of acute angle closure glaucoma following argon laser pan retinal photocoagulation". BMJ Case Reports (2010): bcr1220092511.

9. Agarwal S., et al. "Variability of IOP following laser photocoagulation used in the treatment of diabetic retinopathy". International Journal of Surgery 4.10 (2017): 3433-3440.

10. Birinci H., et al. "Anterior chamber depth and intraocular pressure following panretinal argon laser photocoagulation for 
diabetic retinopathy". Annals of Saudi Medicine 26.1 (2006):

73-75.

11. Tsai JC., et al. "Incidence of Acute intraocular pressure elevation after panretinal photocoagulation". Journal of Glaucoma 4.1 (1995): 45-48.

12. Pavan PR., et al. "Complications of laser photocoagulation". In: We- ingeist TA, Sneed SR. Editors. Laser Surgery in Ophthalmology”. Appleton-Lange 18 (1992): 185-199.

13. Wand M., et al. "Ef- fects of panretinal photocoagulation on rubeosis iridis, angle neovascularization, and neovascular glaucoma". American Journal of Ophthalmology (1986): 332-339.

14. Muqit MM., et al. "Pain responses of Pascal 20ms multi-spot and $100 \mathrm{~ms}$ single-spot panretinal photo-coagulation: Manchester Pascal Study, MAPASS report 2". British Journal of Ophthalmology 94.11 (2010): 1493-1498.

15. Nemcansky J., et al. "Single session of pattern scanning laser versus multiple sessions of conventional laser for panretinal photocoagulation in diabetic retinopathy: Efficacy, safety and painfulness". PLoS One 14.7 (2019): e0219282.

16. Muqit MM., et al. "Single-session vs multiple-session pattern scanning laser panretinal photocoagulation in proliferative diabetic retinopathy: The Manchester Pascal Study". Archives of Ophthalmology 128.5 (2010): 525-533.

\section{Assets from publication with us}

- Prompt Acknowledgement after receiving the article

- Thorough Double blinded peer review

- Rapid Publication

- Issue of Publication Certificate

- High visibility of your Published work

Website: www.actascientific.com/

Submit Article: www.actascientific.com/submission.php Email us: editor@actascientific.com

Contact us: +919182824667

Citation: Tatiana Vélez Osorio., et al. "Secondary Angle Closure Following Panretinal Yellow PASCAL Laser Photocoagulation". Acta Scientific Ophthalmology 4.6 (2021): 27-31. 